\title{
Reduction of Losses in 90 Degree Pipe Bends by Varying Design Parameters using CFD Software
}

\author{
Vinay Sati, Shivasheesh Kaushik, Satyendra Singh, Rahul Kshetri, Rahul Pandey
}

\begin{abstract}
Fluid plays a vital role in various fields of application like industries or domestic use. The efficient transportation of fluid from one location to another has been a major concern persistently. There are certain energy losses occurring in the flow-of fluid whenever there is a change in the path of its flow. In this paper an analysis has been performed across the various general methods employed to generate bent sections, on a 2-D geometric model of a pipe designed using Autodesk Auto CADD 2017. Every alteration of path of fluid flows leads to the loss of momentum of the fluid particles present on the outer layer. This loss of momentum by the particles in turn lead to variation among the fluid parameter like velocity and pressure. These parameters been analyzed in this paper. All the calculations and simulations have been performed on the 2-D axis-symmetric sketches of pipe models, i.e. mesh models under the section of advanced numerical methods using ANSYS R16.0. The fluid being considered in this research activity has been water.
\end{abstract}

Index Terms: K-Epsilon, Naiver-Stokes equation, Advanced Numerical Methods, FLUENT Flow, fillet.

\section{INTRODUCTION}

Fluid has a tendency to flow in layers. As the layer distance increase from the surface of flow, then the higher becomes the velocity gradient $\left(\frac{\partial v}{\partial x}\right)$. Conversely, with the decrease in layer distance from the surface leads to a rise in pressure gradient $\left(\frac{\partial p}{\partial x}\right)$. Further, just at the surface of the body where the layer is in contact with it, due to its low velocity and relatively high-pressure gradient a situation is created as such that the layer moves at a relatively slow speed as compared to other layers present, known as the no-slip condition. The energy which is useful for transformation lies in the free stream region. When a fluid is made to flow over a bend section such that there occurs change in the direction of flow, then the width of the boundary layer starts

Revised Version Manuscript Received on Jun 20, 2019.

Mr. Vinay Sati ${ }^{1}$, Department of Mechanical Engineering, Amrapali Institute of Technology, Haldwani, India.

Shivasheesh Kaushik ${ }^{1}$, Department of Mechanical Engineering, Shivalik College of Engineering, Uttarakhand Technical University, Dehradun, India.

Dr. Satyendra Singh ${ }^{2}$, Department of Mechanical Engineering, B.T.K.I.T

Dwarahat, Uttarakhand Technical University, Dehradun, India.

Dr. Rahul Kshetri ${ }^{2}$, Department of Mechanical Engineering, Shivalik College of Engineering, Uttarakhand Technical University, Dehradun, India.

Rahul Pandey ${ }^{3}$, Department of Mechanical Engineering, Amrapali Institute of Technology, Haldwani, India. increasing resulting in obtaining a reduced free stream region with a lowered energy.

These losses can be reduced by a significant amount if smooth surfaces are provided during the bent section of the fluid transportation which in turn will result in reduction of energy losses.

The smoothness mentioned here should not be mistaken with the smoothness referring to the surface phenomenon because in this paper such case of smoothness has not been discussed where coefficient of friction plays a role and losses due to it occur at bends. Here in this paper smoothness contrasts to sharpness and not to roughness of the surface.

In ideal condition, both the drag and lift component will be equal and hence the energy loss is minimum in such a case. In this paper, we have shown how the negative pressure zones can be removed in cases wherein curved paths are used with illustrated diagrams. Also, the rectification of problem of back flow/reverse flow in the pipe that in leads to lesser variation between input and output parametric quantities. Further, the drag effect can be reduced by providing smooth paths has been indicated in this paper.

\section{LITERATURE REVIEW}

CFD acronym for Computational Fluid Dynamics has evolved over the past few years which enables designers to design customized piping arrangement for a required system as per the requirements organization specifications. Although, CFD offers results with great precision and accuracy, but in general practice the numerical values differ by a certain factor as of various external factors are present in reality. The difference in values is due to CFD being done in an ideal case solution. Most CFD solve the Navier-Stokes equation either in the Lagrangian or Eulerian approach. Apart from these methods, some solve the Boltzmann equation instead of Navier-Stokes equation. CFD can broadly be classified under two categories; namely conventional and accelerated methods.

Accelerated methods are further classified as advanced numerical methods and hardware methods. The advanced numerical methods hierarchy which is explained as hardware methods is beyond the scope of this paper. Advanced numerical methods are further classified into three categories as: -

\section{* Mesh based methods \\ * Mesh free methods \\ * Hybrid methods}

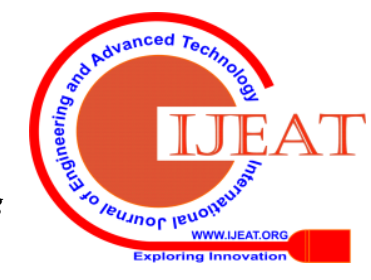


Out of these three methods, the most commonly employed is the mesh-based methods in which there are certain meshed structure created on the geometry of the body. The mesh designs can vary from very fine complex meshes to simple larger meshes; as applicable by the need. Some of the common meshed based methods are listed as: -

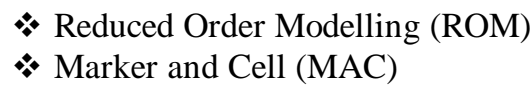

In the mesh free methods, direct surface nomenclature is done by determining the direction of flow and the corresponding parametric values are applied. This is generally used as a macroscopic approach as surface analysis is done in this case. But, in Mesh-based model the microscopic analysis is done. Mesh offers variation of parameters at every instant of the mesh, which depends on how much fine meshing has been done. For in-depth analysis of flow, Mesh-based models are preferred as compared to Mesh free models. The advantage of Mesh free model is that it can provide quick results; which translates into easy adaptation in industries wherein continuous production of goods is taking place. The mesh free methods generally employed are as follows: -

* Smoothed Particle Hydrodynamics (SPH)

* Fast Multipole Method (FMM)

* Method of Fundamental Solutions (MFS)

* Finite Pointset Method (FPM)

* Moving Particle Semi-Implicit Method (MPS)

Our research has been carried out by the conventional methods as they offer a great degree of accuracy, although being slow as compared to accelerated methods. The most popular conventional methods used in practice are: -

\section{* Finite Element Method (FEM) \\ * Finite Volume Method (FVM) \\ * Finite Difference Method (FDM)}

These methods solve the Navier-Stokes equation, which are the governing equations of the CFD Software. These equations describe the conservation of mass, momentum and energy. The method solves equation of complexity order $n^{3}$, where $\mathrm{n}$ is the degree of freedom.

The incompressible Navier-Stokes equation in tensor form is given as: -

a. Conservation of mass $=>\frac{d \rho}{d t}+\rho \frac{\partial u(k)}{\partial x(k)}=0$

b. Conservation of momentum $\rho \frac{d u(i)}{d t}=-\frac{\partial \rho}{\partial x(i)}+\frac{\partial \tau(i j)}{\partial x(j)}+\rho \cdot F(i)$

c. Conservation of energy

$$
\rho \frac{d e}{d t}=-\rho \frac{d u(i)}{d x(i)}+\varphi+\frac{\partial}{\partial x(i)}\left(k \frac{\partial T}{\partial x(i)}\right)
$$

Where $\mathrm{d} / \mathrm{dt}=\partial / \partial \mathrm{t}+\mathrm{u}(\mathrm{i}) \partial / \partial \mathrm{x}(\mathrm{i}), \quad \varphi=\tau(i j) \frac{\partial u(i)}{\partial x(j)}$,

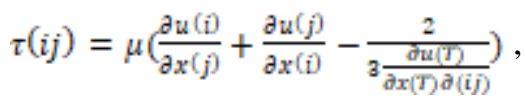
$\mathrm{e}=\mathrm{C}_{\mathrm{v}} \mathrm{T}$ or $\mathrm{h}=\mathrm{C}_{\mathrm{p}} \mathrm{T}$ and $\mathrm{p}=\rho R T$.

\section{RESEARCH METHODOLOGY}

The research was carried out from scratch and performed in multiple stages. The primary stage of the research involved the designing of the pipe models, which was done by using AUTOCADD software.

\section{A. First Stage}

We started with the designs that needed to be checked for their integrity. This was again done in the same software by applying the geometric region tests. Since all parts of the models were perfect regions as obtained from the tests performed on them; the first step in the research process was completed as the geometric bodies had perfect regions indicating that there shall be no losses due to leakage anywhere when we perform the fluid flow simulation.

\section{B. Second Stage}

In the second stage of research, we imported the design files into the CFD software ANSYS R16.0. Then, we assigned the names to the sections of the pipe geometry as inlet, body and outlet. This named selection was done so that analysis at every region of the pipe as a whole body can be performed. This was followed by fine meshing of each section was done in order to provide accurate graphs while simulation is done. Lastly in this stage, we applied the flow direction to the body as inlet>body> outlet respectively.

\section{Third Stage}

The third stage of the research was to select the applicable equations for the meshed model generated. As mentioned, we applied the Navier-Stokes equation and selected the K-Epsilon model to obtain the results for our geometry. These equations have been explained further in the mathematical modelling section.

\section{Fourth Stage}

In the fourth stage, which being the most important stage of the research was to do the simulation of flow. Now using FLUENT we applied the fluid flow through the geometry designed one by one, for each of the case we obtained the velocity and the pressure contours which are illustrated as the variation of the velocity and the pressure component at each point. Also, the graphs obtained indicated the variation of velocity and the pressure within the pipe. 
Multiple number of simulations were done to check the integrity of the results obtained. We, then concluded that the results obtained from the simulation was genuine and hence our research work came to its conclusion. The results obtained are of for ideal conditions and have not been practically verified. There is a possibility of a variation in the values mentioned in the paper by a certain factor.

\section{RESEARCH GAP}

These results were obtained by CFD software are under ideal conditions with standard wall functions. Henceforth, during practical validity we may employ material depending on various factors, some of them being GCI, PVC, SS of varying grades with each possessing different chemical properties. These may affect the values of fluid parameters when tested under these materials. Also, various losses like losses due to friction will be taken into account when practically performed. Various environmental conditions prevailing may also affect the calculations in general practice as this was an ideal case. Due to lack of equipment and certain research tools the practical validity of the models discussed could not be tested and hence comparison between the practical and ideal approach could not be done.

\section{MATHEMATICAL MODELLING}

There are four models used for this analysis:

1) The first being a pipe bent at 90 degrees sharply at both the ends,

2) The second model is a pipe bent at 90 degrees using 2 fillets,

3) The third model consists of a fillet at the inner section to provide the 90 degrees bend keeping the outer section is kept at sharp 90 degrees; and

4) The fourth model consists of a fillet at the outer section to provide the 90 degrees bend, keeping the inner section bent at sharp 90 degrees.

All of the pipe models are of similar dimensions as described and the direction of flow is also the same

\section{A. Named Reference}

We have used named references further for these pipes,

- The first pipe described be referred to as T-90 and

- The second one described is F-90,

- The third pipe be referred as I-90 and

- The fourth pipe referred as E-90.

For the geometric modelling, all models have been constructed considering +-0.12 m tolerance.

a) The specifications of T-90 are :-

1. Diameter $=0.80 \mathrm{~m}$

2. Base length $=2.00 \mathrm{~m}$

3. Boundary length $=11.2 \mathrm{~m}$

4. Surface Area $=3.84 \mathrm{~m}^{2}$

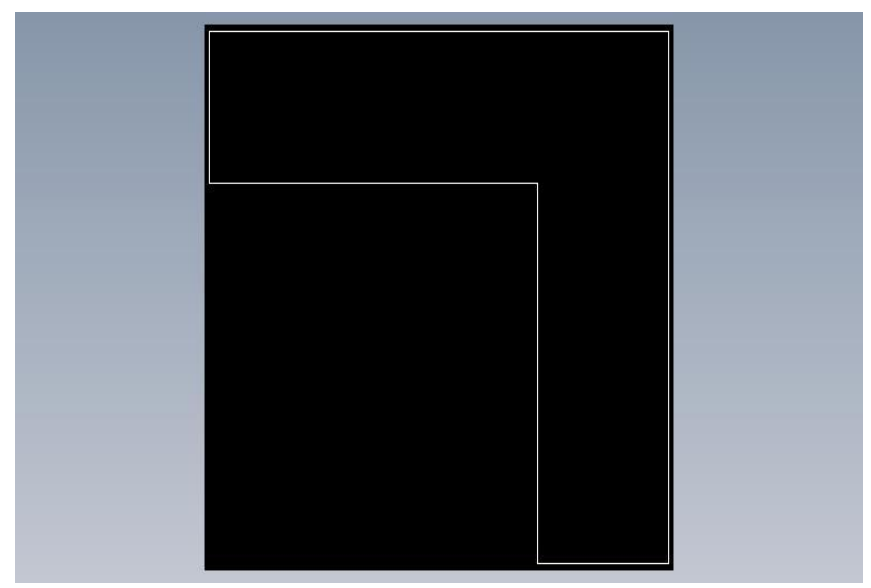

Figure- T-90

b) The specifications of F-90 are :-

1. Diameter $=0.80 \mathrm{~m}$

2. Base length $=1.35 \mathrm{~m}$

3. Boundary length $=11.03 \mathrm{~m}$

4. Arc lengths $=1.23,1.30 \mathrm{~m}$

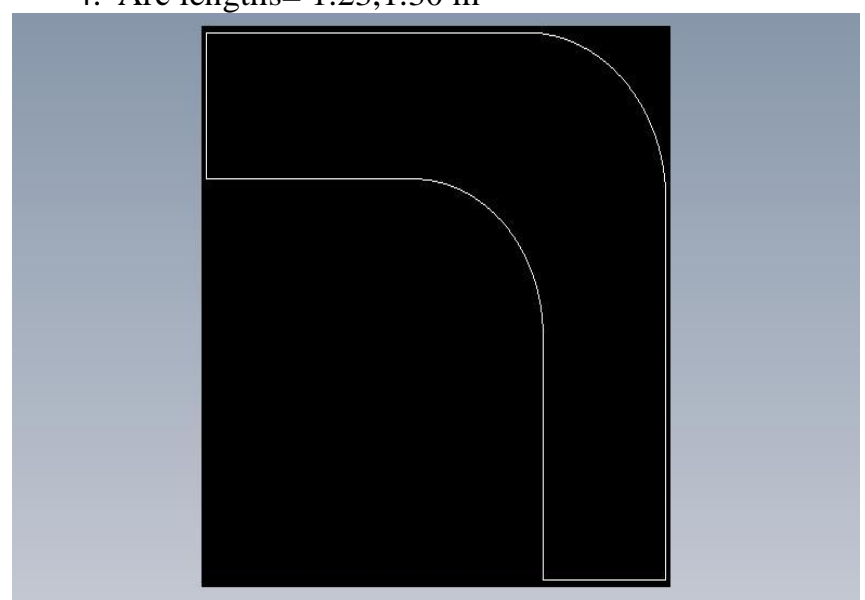

Figure- F-90

c) The specifications of I-90 are:-

1. Diameter $=0.80 \mathrm{~m}$

2. Base length $=1.35 \mathrm{~m}$

3. Boundary length $=11.13 \mathrm{~m}$

4. Arc length $=1.23 \mathrm{~m}$

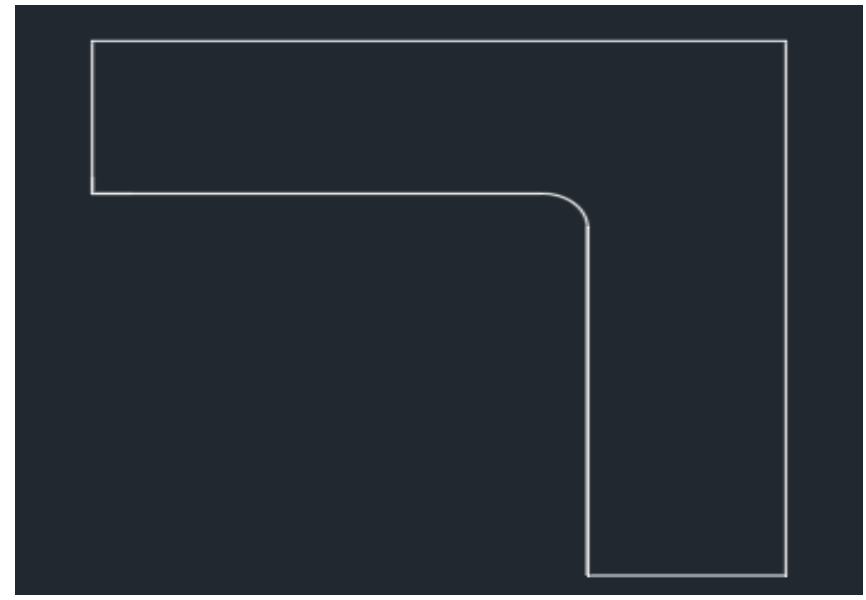

Figure- I-90 
d) The specifications of E-90 are:-

1. Diameter $=0.80 \mathrm{~m}$

2. Base length $=2 \mathrm{~m}$

3. Boundary length $=11.1 \mathrm{~m}$

4. Arc length $=1.31 \mathrm{~m}$

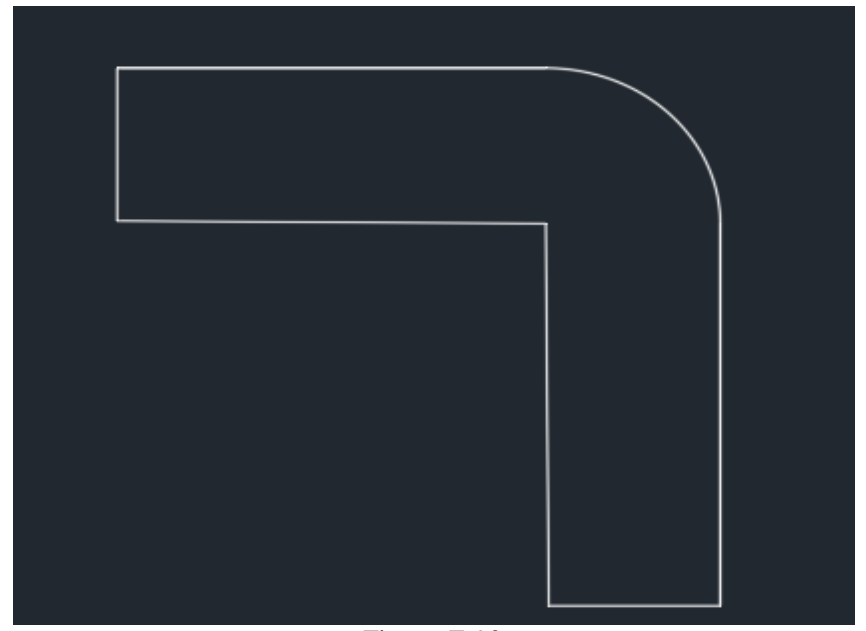

Figure- E-90

The above-specified dimensions of all four of the Models have the same discharge capacity although having varying geometries. Since all the forces due to turbulence are neglected, we have done the simulation by applying Naiver-Stokes equation and K-Epsilon model.

Let $\mho_{\text {net }}$ be the resultant velocity of fluid in 2-D then,

$\xi_{\text {net }}=\mho_{\text {drag }} \cos \Theta+\xi_{\text {lift }} \sin \Theta \quad---(1.1)$

where, $\mho_{\text {drag }}$ is the drag velocity, $\mho_{\text {lift }}$ is the lift velocity and $\Theta$ be the angle formed by the resultant fluid flow between the drag and lift component plane.

The fluid from region 1 to region 2 as shown on the flow diagram, considering that no mass has been stored thus rate of mass inflow=rate of mass outflow. Applying momentum integral and continuity equations at these regions-

Continuity Equation

$\frac{\delta(\rho \uplus)}{\delta x}+\frac{1}{r} \frac{\delta(\rho r \vartheta)}{\delta r}$

Momentum Equations:

Axial component (z-component)

$\rho \vartheta\left[\frac{\delta \uplus}{\delta r}+\forall \frac{\delta \uplus}{\delta x}\right]=\frac{\delta p}{\delta x}+\frac{\delta}{\delta x}\left(\mu \frac{\delta \uplus}{\delta x}\right)+\frac{1}{r} \frac{\delta}{\delta r}\left(\mu \frac{\delta \mathrm{\psi}}{\delta r}\right)+$ $\frac{\delta}{\delta x}\left(\mu \frac{\delta \mathrm{z}}{\delta x}\right)+\frac{1}{r} \frac{\delta}{\delta r}\left(\mu \frac{\delta \mathrm{z}}{\delta r}\right)$

$---(1.3)$

Radial component(r-component)

$\rho\left[\vartheta \frac{\partial y}{\partial r}+\forall \frac{\partial y}{\partial x}\right]=-\frac{\partial p}{\partial z}+\frac{\delta}{\partial x}\left(\mu \frac{\partial y}{\partial x}\right)+\frac{1}{\partial} \frac{\partial}{\partial r}\left(r \mu \frac{\partial v}{\partial r}\right)+$ $\frac{\delta}{\partial x}\left(\mu \frac{\partial \psi}{\partial r}\right)+\frac{1}{r} \frac{\delta}{\partial r}\left(r \mu \frac{\partial \theta}{\partial r}\right)-2 \mu \frac{\partial}{r 2}+\rho \frac{\mathrm{W} 2}{r}$

$---(1.4)$

Tangential component ( $\Theta-$ component)

$\rho\left[\vartheta \frac{\partial p}{\partial r}+\forall \frac{\partial p}{\partial x}\right]=\frac{\delta}{\partial x}\left[\mu \frac{\partial p}{\partial x}\right]+\frac{1}{r} \frac{\delta}{\partial r}\left[r \mu \frac{\partial p}{\partial r}\right]-\frac{2}{r} \frac{\delta}{\partial r}[\mu \phi]$ $---(1.5)$

Here $\xi, \vartheta, \mathrm{w}$ are the velocity components along $\mathrm{z}, \mathrm{r}, \theta$ directions respectively and the variables $\phi=r w$ and $\mu=\mu_{\text {eff. }}$

\section{INPUT PARAMETERS}

Analysis of the flow conditions was done using ANSYS Fluent 16.0 CFD Software. These equations are solved by converting complex partial equation into simple algebraic equation. All the geometries T, F, I \& E90 are 2-D rigid solids comprising of 1 region 3 named selections as inlet, outlet, and path. The above mentioned 2-D geometries are used to solve the momentum and energy equations. The initial phase is to define the velocity of flow at inlet section in upstream path. The acceleration due to gravity has been considered as $9.81 \mathrm{~m}^{2} / \mathrm{sec}$. The standard wall functions are applied to the к- $\varepsilon$ turbulence equations for solving the problems. The initial velocity given to all the T, F, I \& E 90 geometries is $1 \mathrm{~m} / \mathrm{sec}$

\section{RESULTS AND OBSERVATIONS}

The input and output charts of the pressure and velocity indicating variation in their respective values were obtained, also the velocity and pressure contours obtained are as shown below: -

\section{a) Velocity and Pressure Parametric charts}

\section{1. $\mathrm{T}-90$}

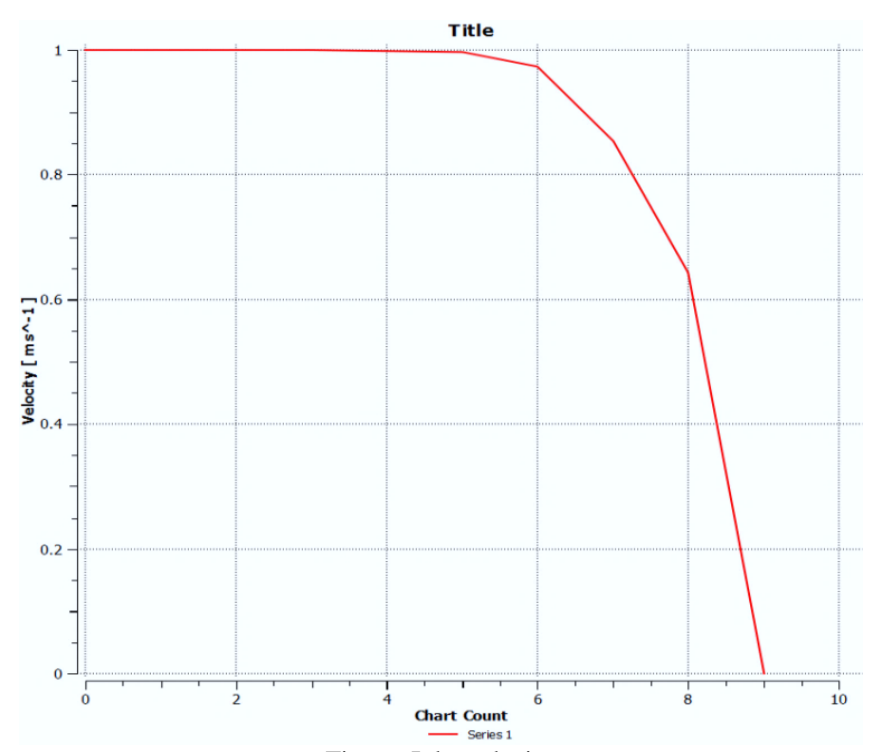

Figure- Inlet velocity

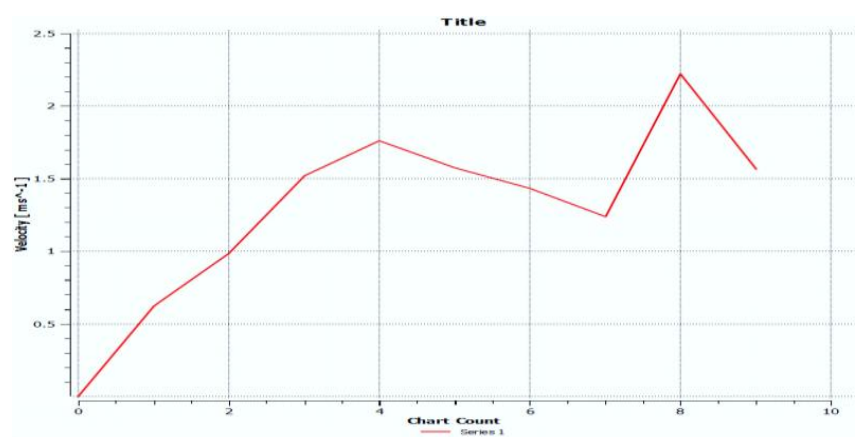

Figure- Outlet velocity 


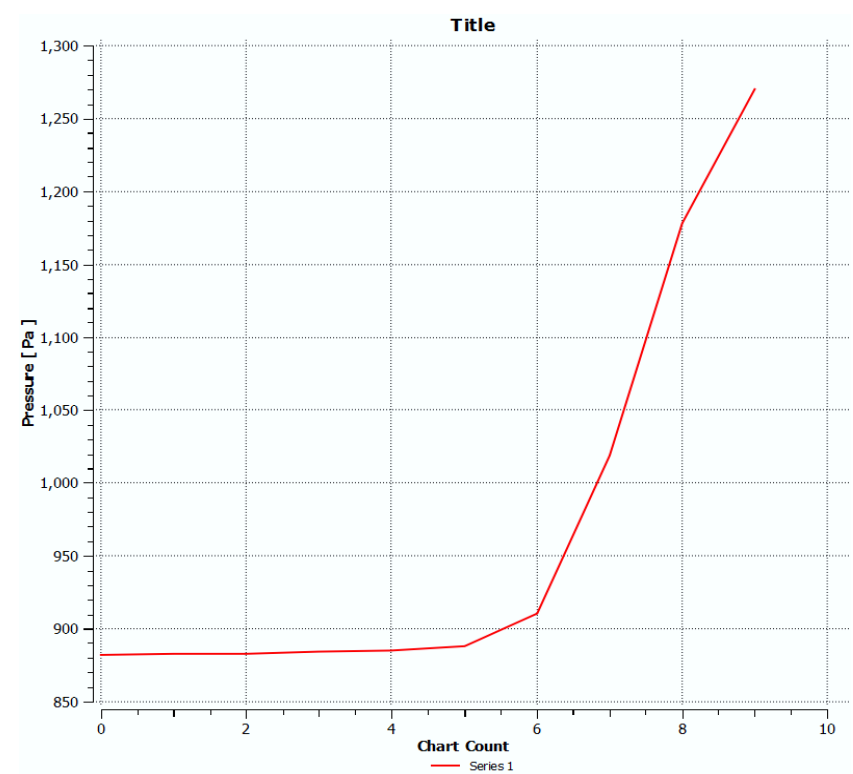

Figure- Inlet Pressure

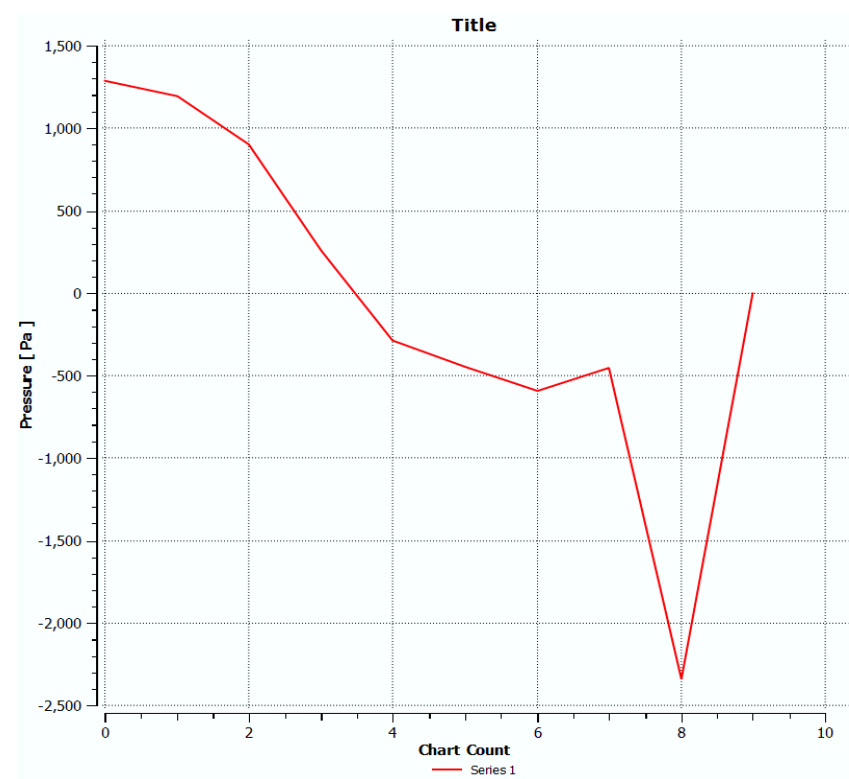

Figure- Outlet Pressure

2. $\mathrm{I}-90$

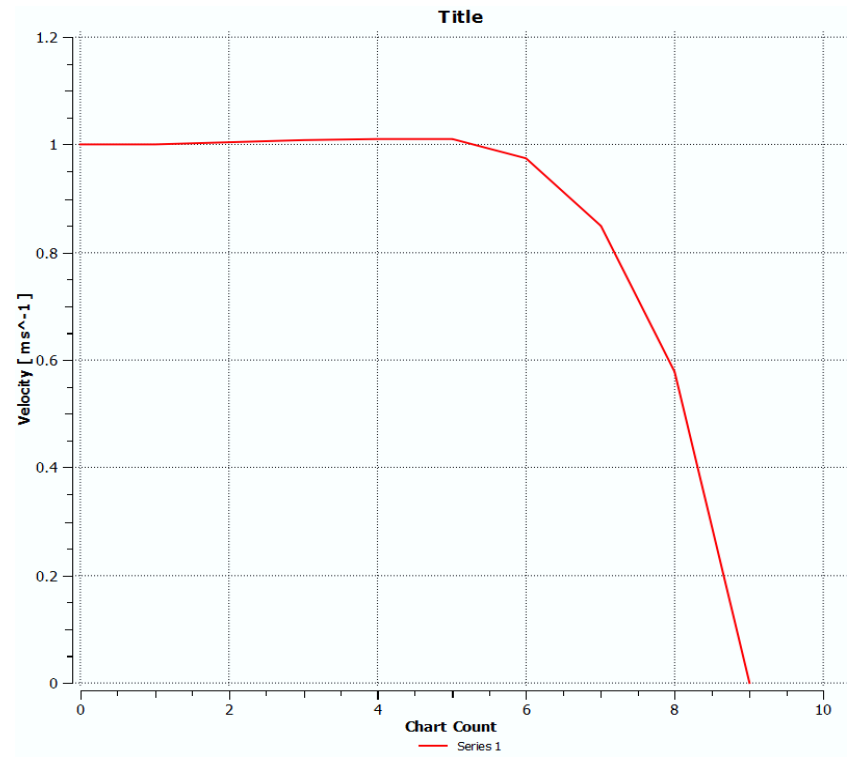

Figure- Inlet velocity

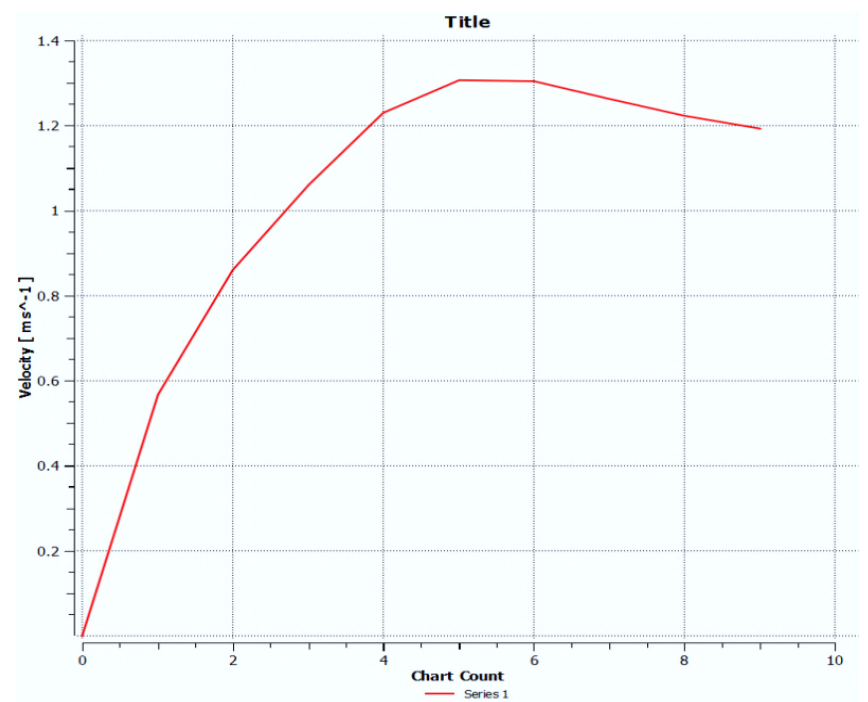

Figure- Outlet velocity

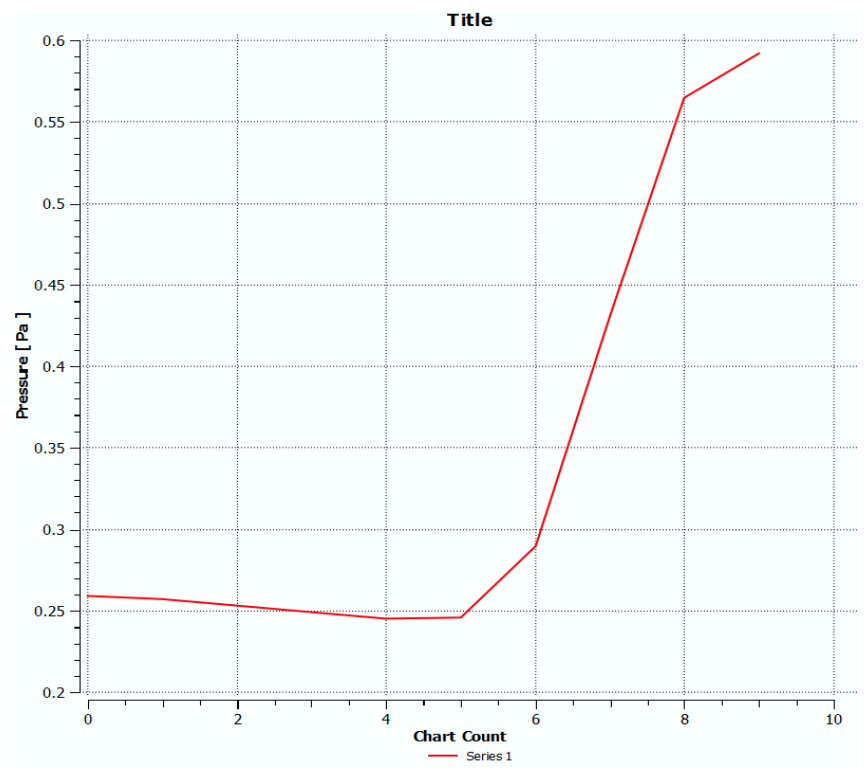

Figure- Inlet Pressure

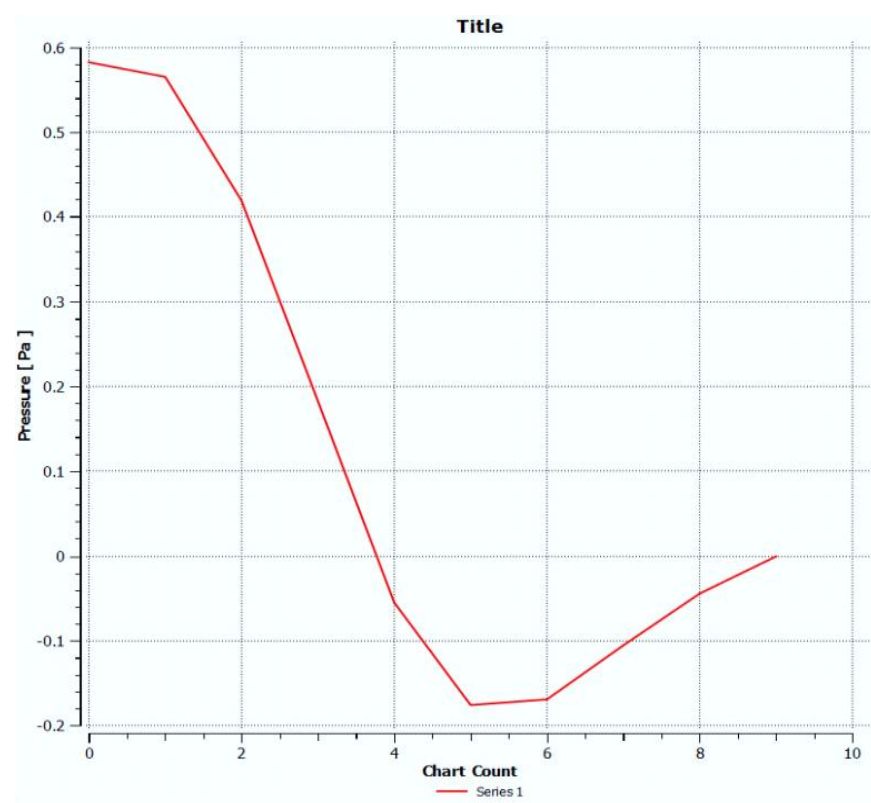

Figure- Outlet Pressure

\section{Published By:}

Blue Eyes Intelligence Engineering \& Sciences Publication 
3. E-90

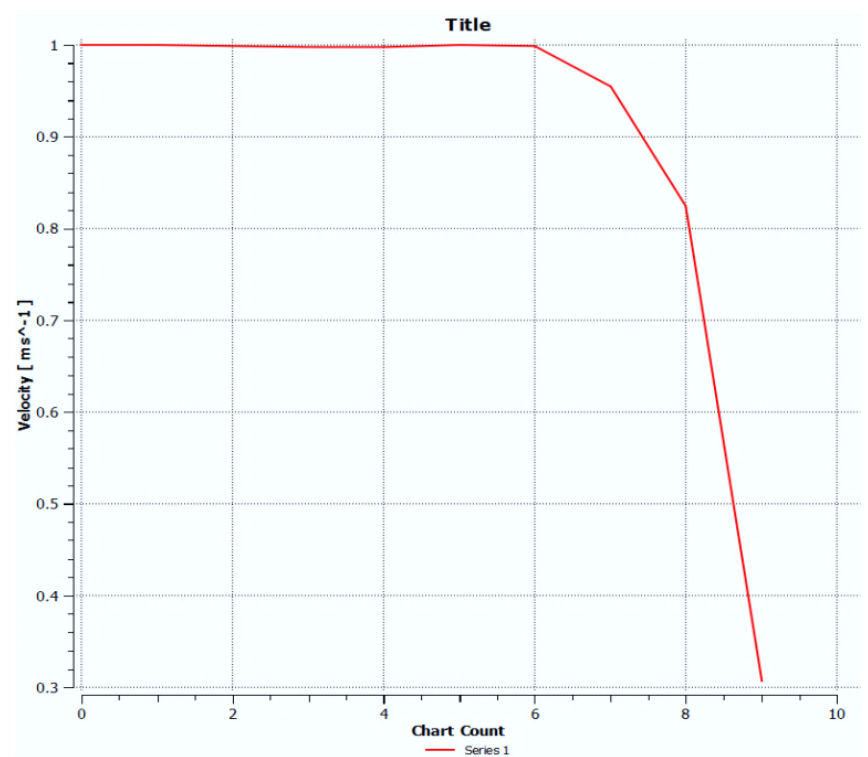

Figure- Inlet velocity

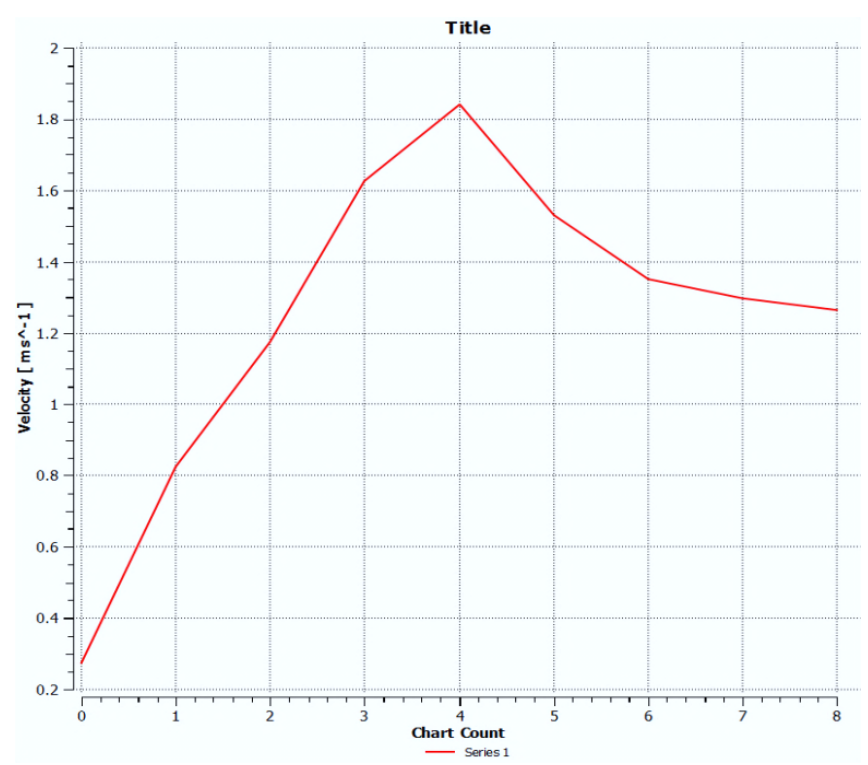

Figure- Outlet velocity

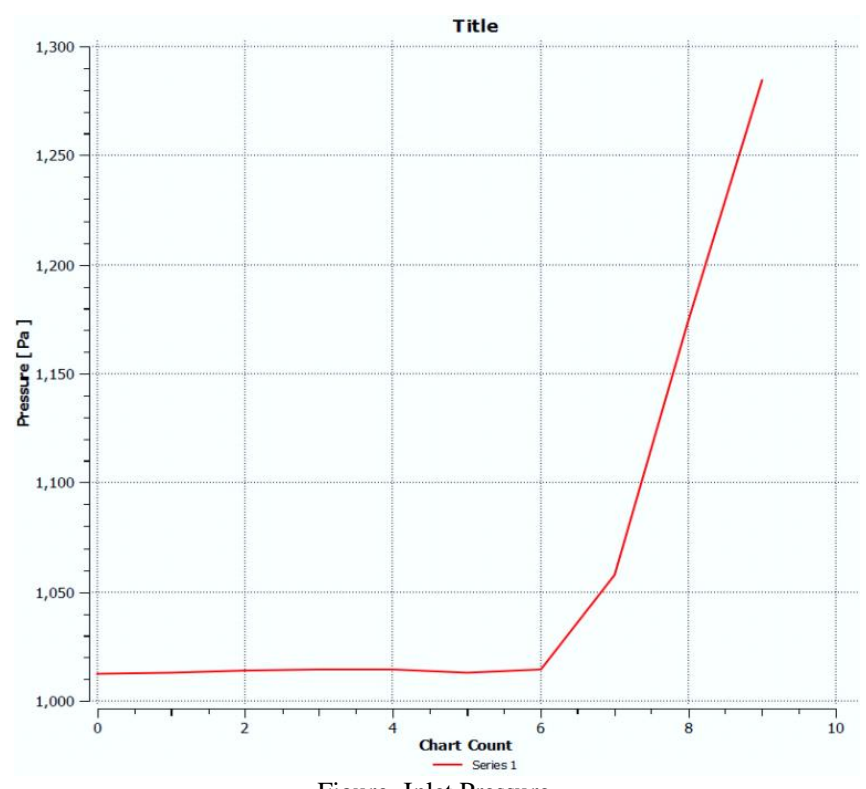

Figure- Inlet Pressure

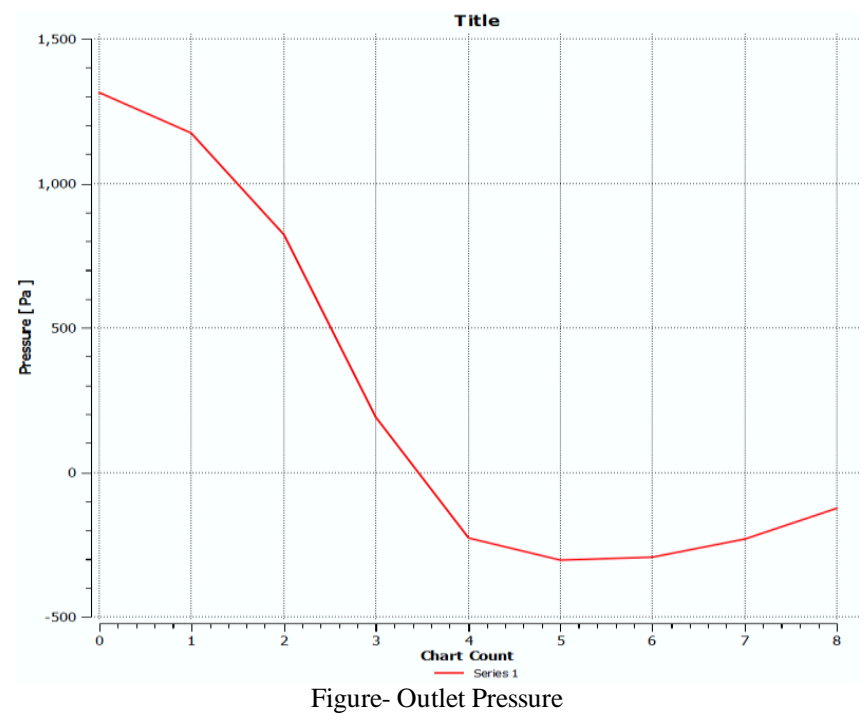

4. F-90

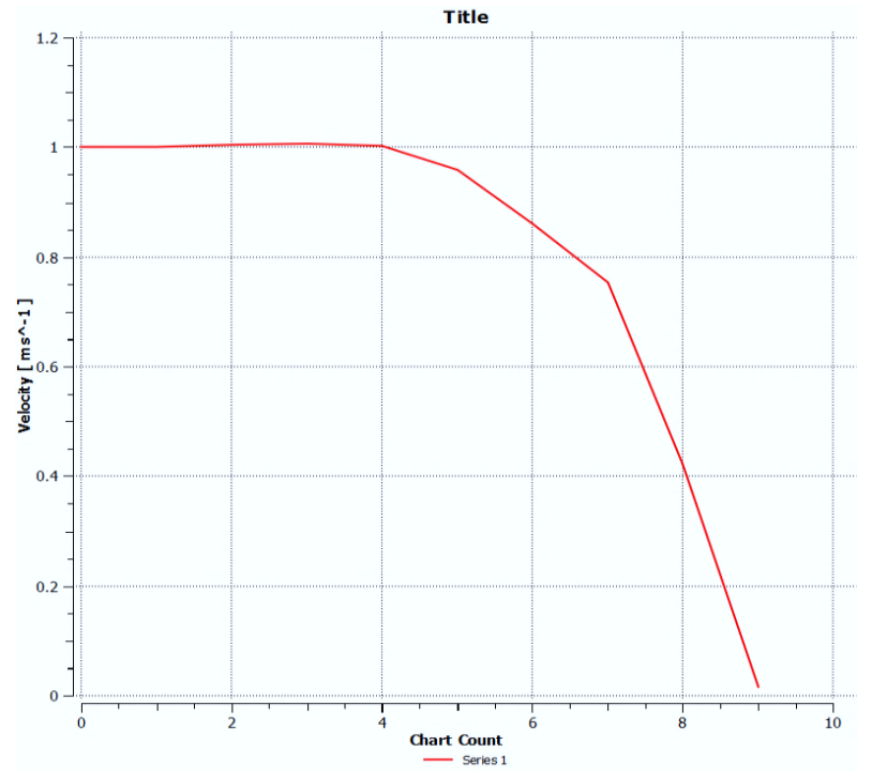

Figure- Inlet velocity

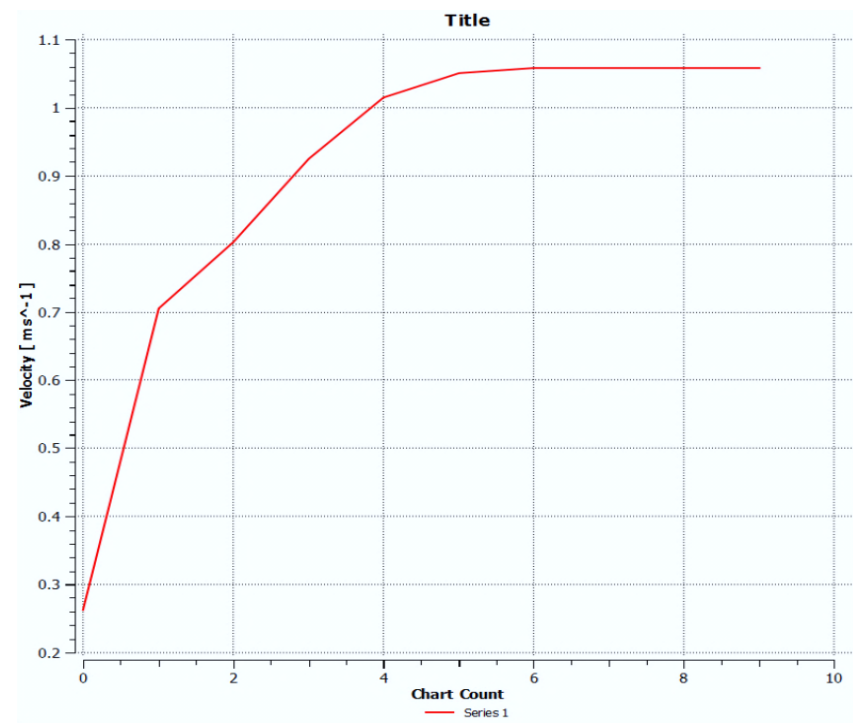

Figure- Outlet velocity 


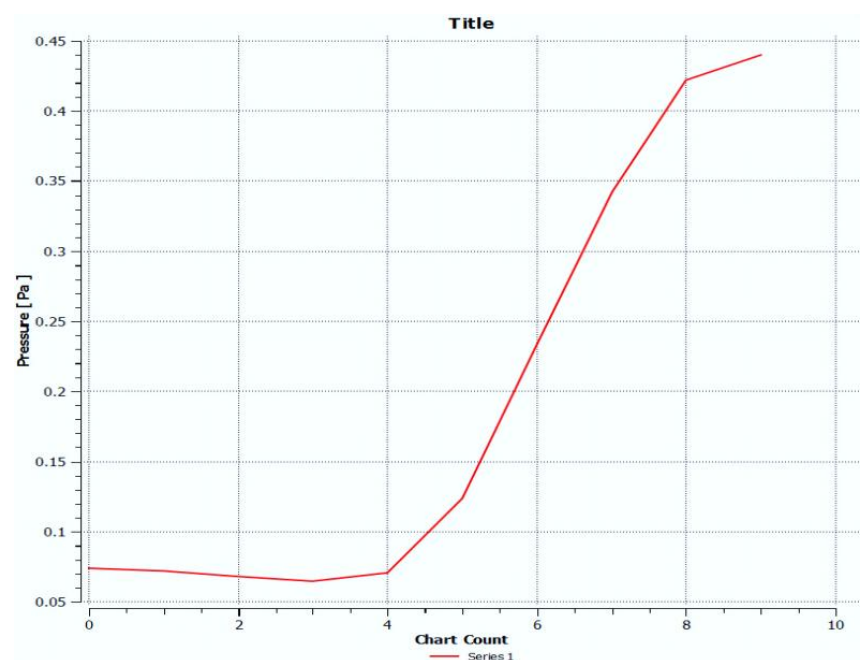

Figure- Inlet Pressure

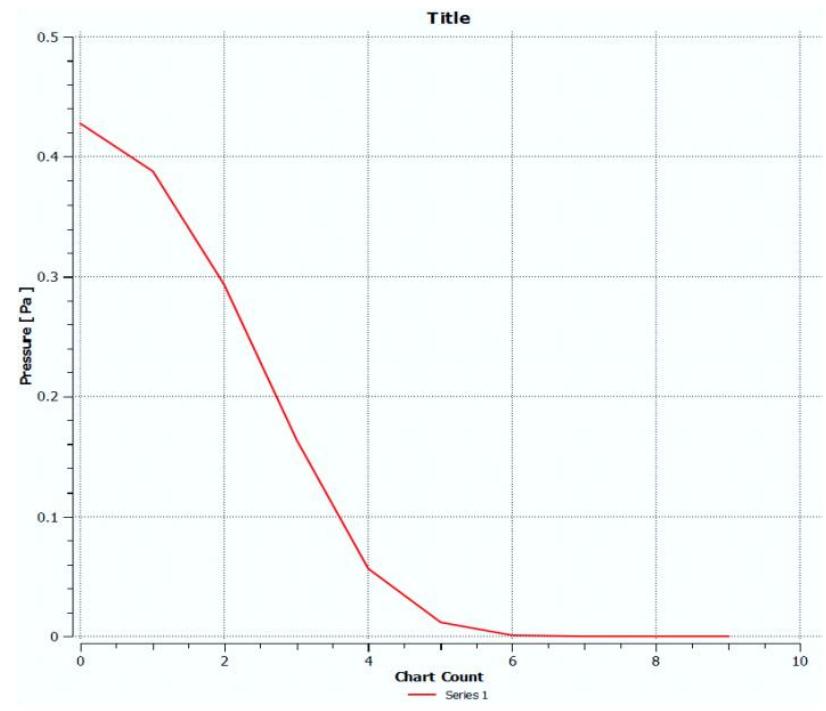

Figure- Outlet Pressure

b) Pressure and Velocity Contours

I. T-90

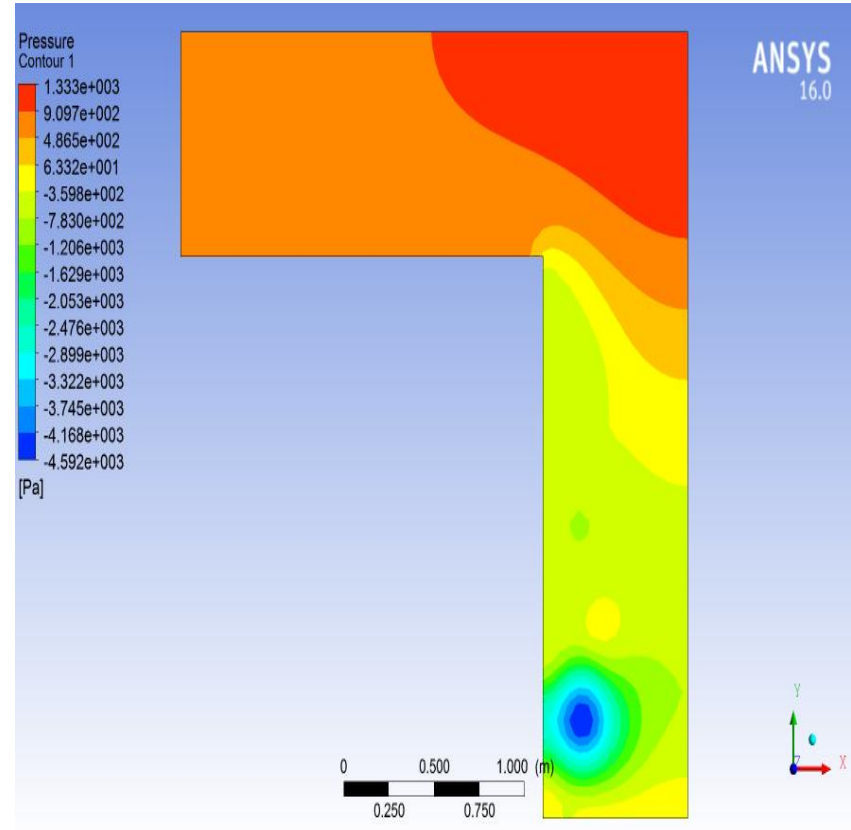

Figure- Pressure Contour

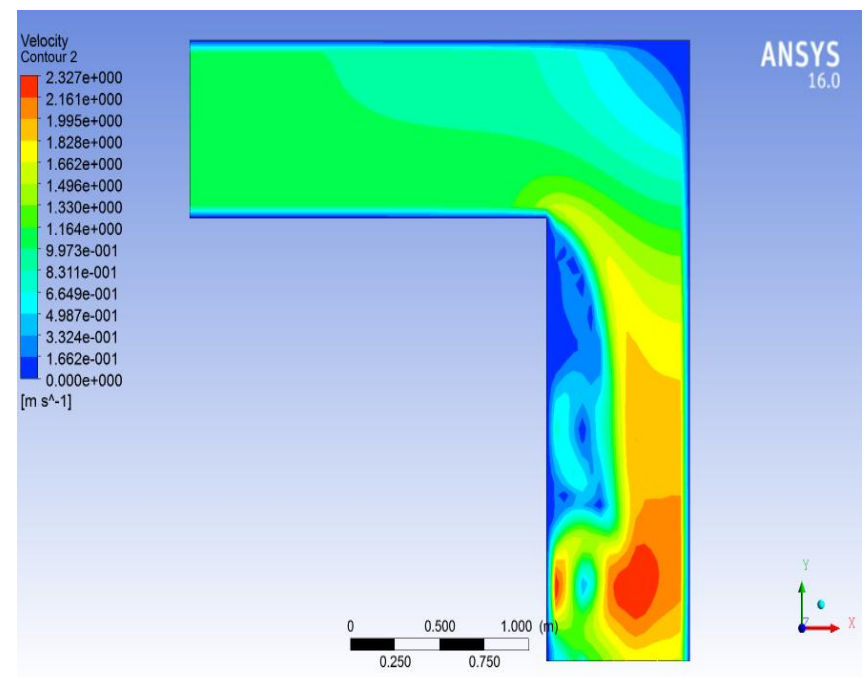

Figure- Velocity Contour

II. I-90

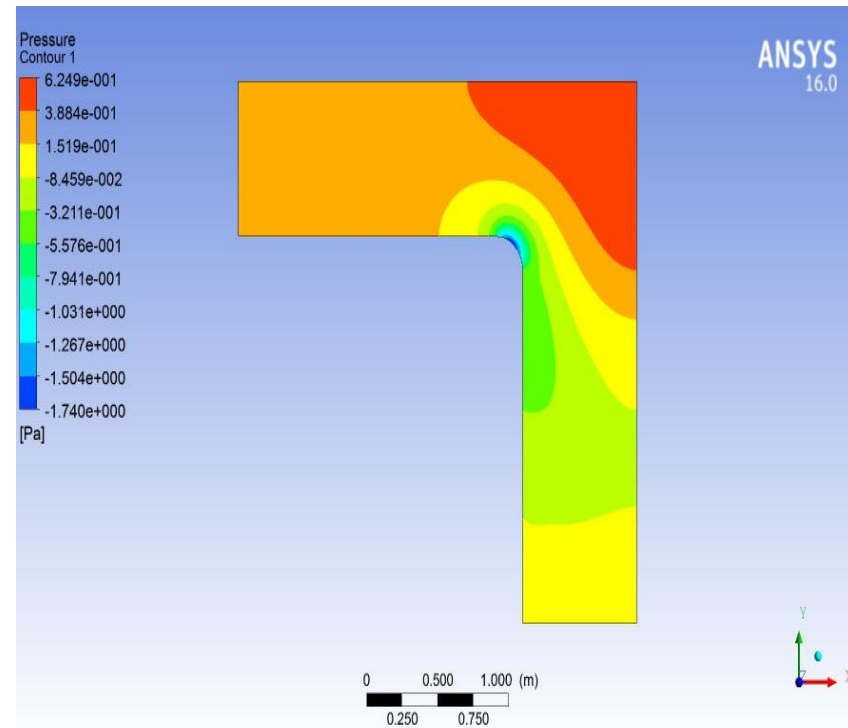

Figure- Pressure Contour

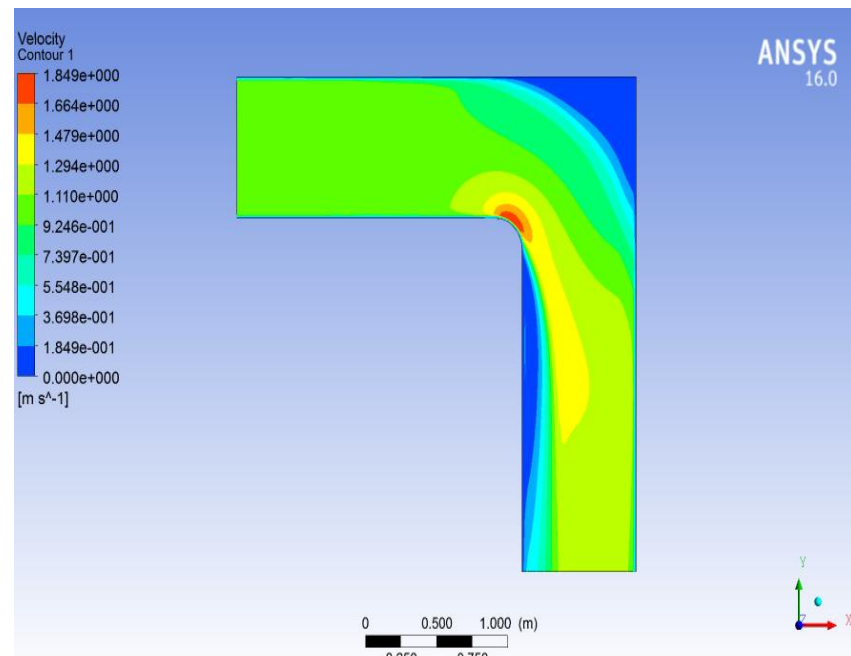

Figure- Velocity Contour 


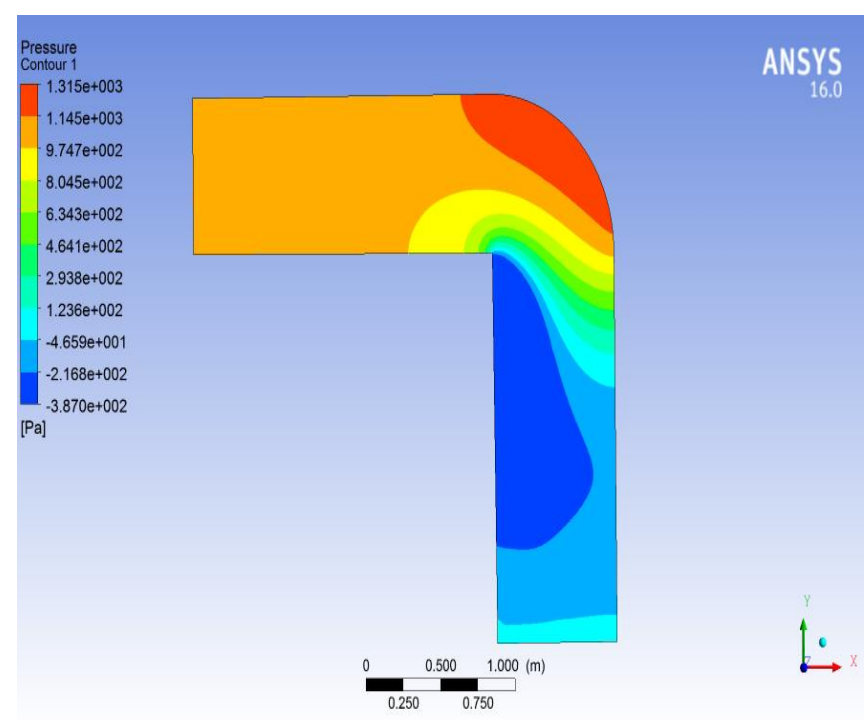

Figure- Pressure Contour

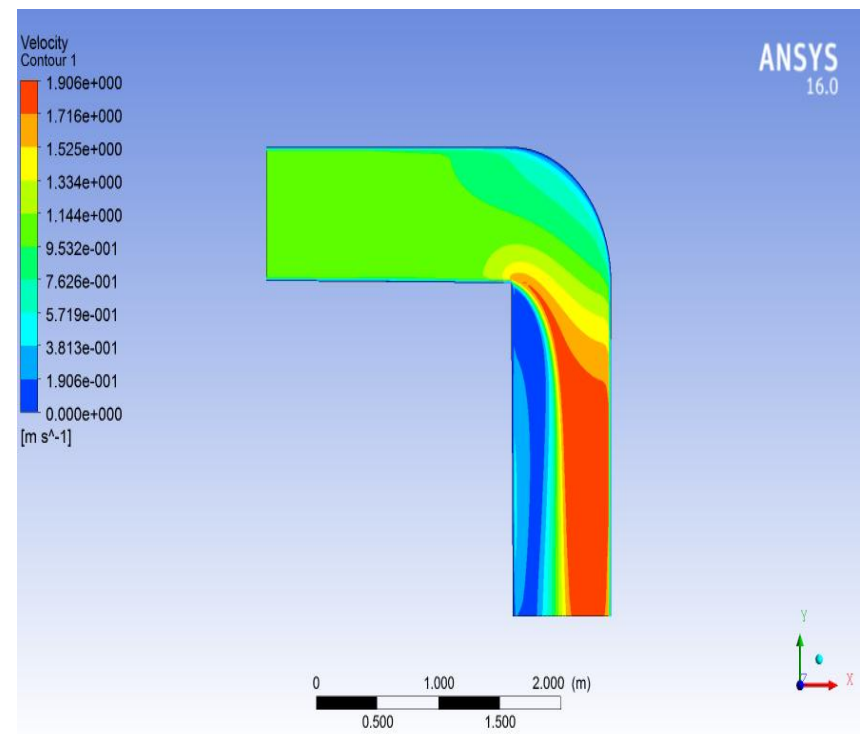

Figure- Velocity Contour

\section{F-90}

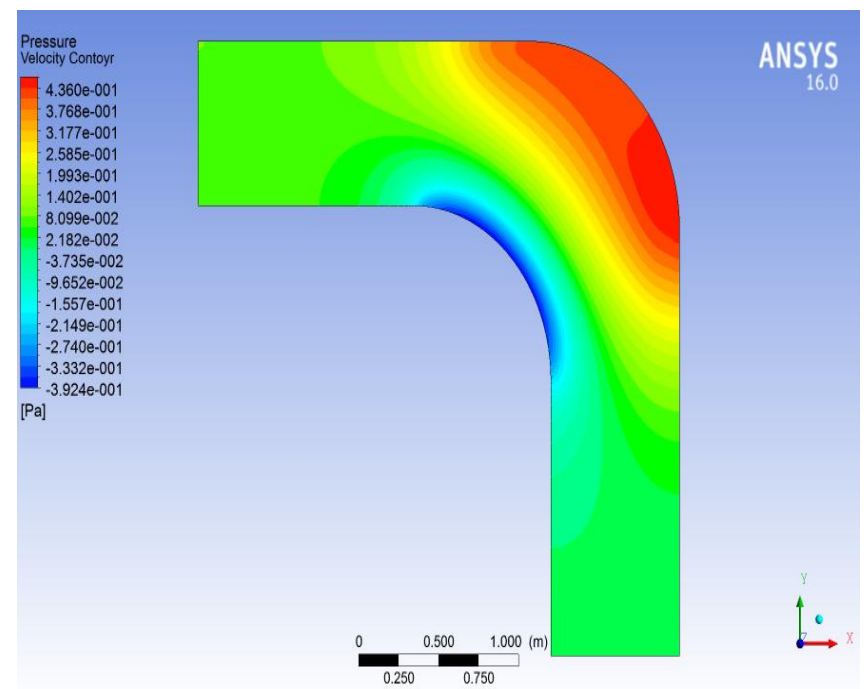

Figure- Pressure Contour

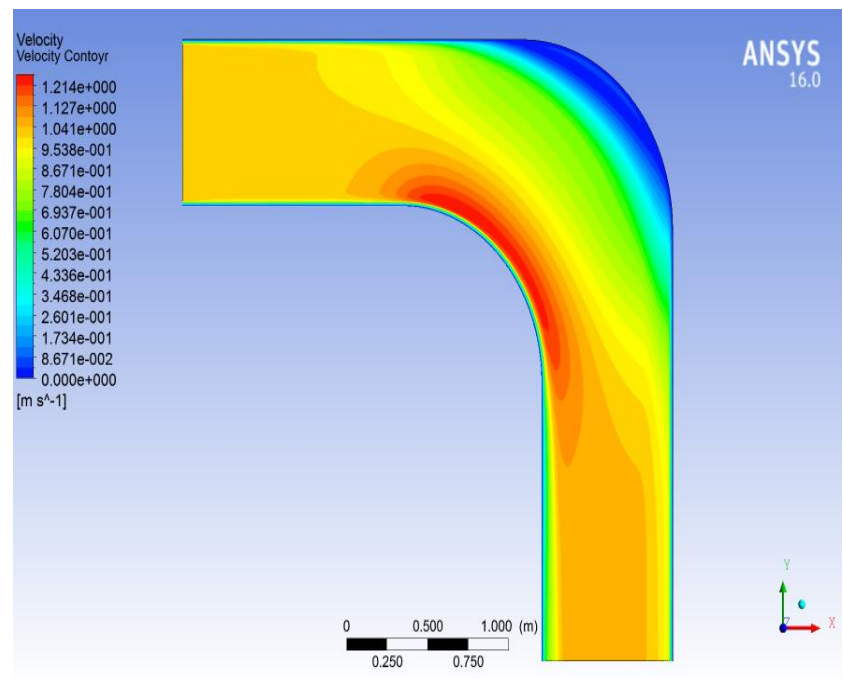

Figure- Velocity Contour

c) Observation

\section{A. Model T-90}

In the case of T-90, the input velocity was of the order of $1.164 \mathrm{~m} / \mathrm{sec}$ uniformly distributed at its cross-sectional area, but later on during the bend we see that due to pressure difference at the boundary certain region have the velocity of the order of $0 \mathrm{~m} / \mathrm{sec}$ which can cause backflows in case of heavy discharge volumes. Later when the fluid from the bend to the exit, i.e. downwards then the velocity from $0 \mathrm{~m} / \mathrm{sec}$ from the bend increase and lies in the region of $1.662 \times 10^{-001}$ to $8.311 \times 10^{-001} \mathrm{~m} / \mathrm{sec}$ which constitutes the major area of the output section of the pipe and the remaining smaller region of the output section has a velocity of order $1.828 \mathrm{~m} / \mathrm{sec}$. Now, in the pressure we observe that the input section had a pressure well maintained at $4.865 \times 10^{2} \mathrm{~Pa}$ which towards the sharp bend increased to $1.333 \times 10^{002} \mathrm{~Pa}$ creating the conditions for the backflow of the fluid. we then see now that the pressure at the section where velocity was $8.311 \times 10^{-001}$ $\mathrm{m} / \mathrm{sec}$ reached to $-4.592 \times 10^{003} \mathrm{~Pa}$ creating a sudden drop in the pressure just before the output section and most of the output section had the pressure of the order of $-1.629 \times 10^{003}$ $\mathrm{Pa}$. This was all the variations as observed in the model T-90.

\section{B. Model I-90}

Now the observations made for the model I-90 were as: - In this model as discussed earlier we had provided an internal fillet at one section keeping the other dimensional parameters same. The input velocity at he cross section was observed to be $1.110 \mathrm{~m} / \mathrm{sec}$ which had reached the value 0 $\mathrm{m} / \mathrm{sec}$ again at the sharp bent section, but by providing the internal fillet we observed that the velocity reached 1.849 $\mathrm{m} / \mathrm{sec}$ at the fillet section and also the zone of no slip condition, i.e. $0 \mathrm{~m} / \mathrm{sec}$ was significantly reduced as compared to T-90 model. The output velocity obtained was of the order of 0.9246 to 1.1294 $\mathrm{m} / \mathrm{sec}$ with $1.1294 \mathrm{~m} / \mathrm{sec}$

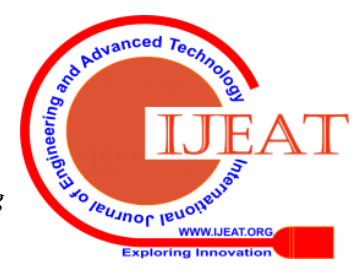


acquiring a major portion of the cross section of the output. In terms of pressure, $3.884 \times 10^{-001} \mathrm{~Pa}$ was the pressure at the inlet of the pipe section maintained constant through till the bend. At the sharp edge bend like the previous case there was high pressure zone present of the order of $6.249 \times 10^{-001} \mathrm{~Pa}$ which cause the backflow in the section when large volume of fluid flows; now by providing the internal fillet at the section we observed that the pressure reached a lowest value at it of $-1.740 \mathrm{~Pa}$ which was later in the flow normalized and was of the order of $1.519 \times 10^{-001} \mathrm{~Pa}$. This value was constant throughout the outlet section of the pipe.

\section{Model E-90}

Observing the reading of the model E-90, the velocity at the inlet section was constant at $1.144 \mathrm{~m} / \mathrm{sec}$ up to the bent section. In this case the external bent was provided, hence we observe that $0 \mathrm{~m} / \mathrm{sec}$ velocity zone was dramatically reduced as compared to the previous cases, but it prevailed at the internal section of the model. Turbulence was created during the next section of pipe with majority of the velocity in the band of $0-3.813 \times 10^{-001}$ while the remaining narrow portion of the output section had velocity of the order of $1.906 \mathrm{~m} / \mathrm{sec}$. In terms of pressure, the inlet pressure was $1.145 \times 10^{003} \mathrm{~Pa}$ and was constant up to the bent section; now with the external curved path provide, we saw the reduced zone of the backflow where pressure was of the order of $1.315 \times 10^{003} \mathrm{~Pa}$. Now before reaching the output section of the model, the pressure tried to stabilize and output was obtained at a constant pressure of $1.236 \times 10^{003} \mathrm{~Pa}$.

\section{D.Model F-90}

Now coming on to the last model, F-90 in which the velocity at the inlet section was kept constant about 1.041 $\mathrm{m} / \mathrm{sec}$, later we see that here since both the surfaces for the bend are curved, the region of backflow exists but constitutes a narrow zone as evident in the diagram, the velocity reaches its peak value at the internal section of $1.214 \mathrm{~m} / \mathrm{sec}$ but overall during the outlet section, there is no turbulence found in the flow and output has the same velocity at inlet of 1.041 $\mathrm{m} / \mathrm{sec}$. Regarding pressure parameters, the inlet section had a constant pressure throughout at $1.402 \times 10^{-001} \mathrm{~Pa}$ which later on reaching the bent section had a higher pressure zone at the exterior section which causes backflow; the pressure prevailing there was of the order of $4.360 \times 10^{-001} \mathrm{~Pa}$, later on as we had employed both the sections as curved in this case, the turbulence in the flow before reaching the outlet was reduced significantly and the pressure obtained at the outlet section was same as that at inlet section, i.e. $1.402 \times 10^{-001} \mathrm{~Pa}$.

\section{INFERENCE}

We infer from this research that sharp bends employed in pipes during fluid flows leads to a greater degree of the momentum loss which leads to the reduced velocity of flow. At the sharp edges, the air creates a negative pressure zone leading to backflow which in-turn leads to reduction in the discharge velocity. Such sharp bend may should be employed in cases where reduction of velocity is needed at the discharge. The curved surfaces (fillet) on the other hand provides a smooth transition for the fluid particles; hence leading to a reduced loss in the momentum possessed by the particles. The advantage of curved surface (fillet) is that the air does not get entrapped during the flow, leads to reduced backflow by a significant factor. As backflow is almost eliminated; the continuity equation remains valid by a greater degree in comparison to that in the sharp 90-degree bend. As on for fillets how a single and dual filleted surface reduces the momentum loss is evident from the result. Generally, fillets are employed in practical uses as velocity at input is not lost completely which invariably means that output velocity remains almost in the range of input velocity. Summing up we can say that the flow tends to greater degree of continuity when fillet is employed as evident from the above-mentioned results.

\section{FUTURE SCOPE}

This paper gives an overview on the control of the flow of fluid in pipe bends. Further, it also highlights the variations of velocity and pressure parameters within the flow. This in turn, can be further worked upon by using various different fluids with variable coefficient of viscosity in comparison to water. Also, the dimensions can be varied while using different fluids so as to derive the relation between the fluid flow and the surface area. Further, depending upon the type of fluid, we can vary the dimensions and the conditions prevailing to control the fluidity of the flow, as here standard wall functions were used.

\section{CONCLUSIONS}

We must employ fillets while providing bends in the course of the pipeline layout during transportation of fluid, to reduce the energy losses and henceforth increase our Input to Output ratio in terms of velocity, from the above results it is evident that providing a smooth curved path results in greater efficiency as compared to sharp edged bends. We conclude through this research activity that curved path is better than sharp edged path if high velocity discharge is required at the output of the section. In case a low velocity, high pressure discharge is required then we can employ the 90-degree bent.

\section{EDITORIAL POLICY}

We are submitting this manuscript with mutual consent of all the authors involved in it. There are no competing interests among the authors regarding any phase or part of the manuscript. If any part of the manuscript is to be replicated in any manner, the decision rests with the authors for providing the permission for the same. No content of this manuscript should be replicated without any prior permission granted by the authors. The publisher holds the rights to make prior changes before publishing the manuscript, but the corresponding author must be informed about the changes.

\section{REFERENCES}

1. S K Som, Suman Chakraborty"Introduction to fluid mechanics and fluid machines" 3e, McGraw Hill

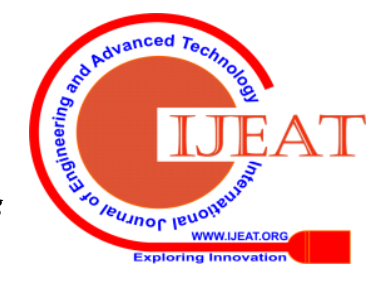


International- ISBN 978-0-07-132919-4

2. Yunus A. Cengel, John M. Cimbala- "Fluid Mechanics Fundamentals and Applications" 3e, McGraw Hill International-ISBN 978-93-392-0465-5

3. Fox R. W., A. T. McDonald, and P. J. Pritchard, "Introduction to Fluid Mechanics", 5e, John Wiley \& Sons, Inc., 2004.

4. Laufer, J., "The structure of turbulence in fully developed pipe flow", NACA Report, NACA-TN-2954 (1953).

5. Vinay Sati et al, "Hydrodynamic and Thermal Analysis in Pipe Flow using ANSYS Software", International Journal of Research and Technology, ISSN: 2278-0181, March 2015.

6. John D. Anderson Jr, Computational Fluid Dynamics, McGraw Hill Book Company .

7. Literature Review of accelerated CFD Simulation Methods towards Online Application, Md Lokman Hosain and Rebei Bel Fdhila.

8. McKee, S., Review the MAC Method, Computer \& Fluids 37 (2008) p.907-930.

9. Valizadeh, A., et. al. Modeling Two-Phase Flows Using SPH Method, J. of Applied Sciences 8(21): p.3817-3826, (2008).

10. Greengard, L., Kropinski, M. C., An Integral Equation Approach to the Incompressible Navier-Stokes Equations in Two Dimensions, SIAM J. Sci. Comput. Vol. 20, No. 1, p. 318-336 (1998).

11. Kuhnert, J., Tiwari, S., Finite pointset method based on the projection method for simulations of the incompressible Navier Stokes equations, Fraunhofer Institute for Industrial Mathematics, Kaiserslautern, Germany.

12. Succi, S, The Lattice Boltzmann Equation for Fluid Dynamics and Beyond, ISBN-13: 978-0198503989, Oxford University Press, Oxford, New York, 2001

13. Tokura, S., Comparison of Particle Methods: SPH and MPS, 13th International LS-DYNA User Conference

14. Rahul Pandey, Vinay Sati, Shivasheesh Kaushik, Dr. Anirudh Gupta, Hydrodynamic flow analysis across bent sections of pipe using CFD software, Vol 4 Issue 10 IJERT ISSN No- 2278-0181

15. Vinay Sati, Shivasheesh Kaushik, Dr. Anirudh Gupta, Hydrodynamic and Thermal Analysis in Pipe Flow using ANSYS Software, Vol 4 Issue 03 IJERT ISSN No- 2278-0181

\section{AUTHORS PROFILE}

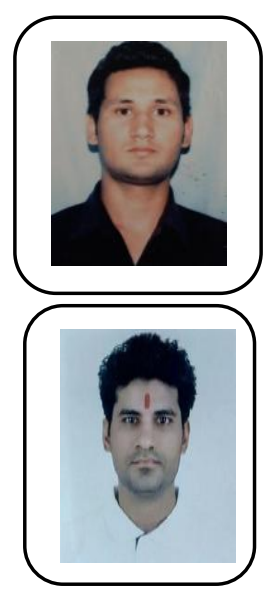

Vinay Sati is an Assistant Professor at Amrapali Group Of Institute, Haldwani. He received his M.Tech. from B.T.K.I.T formerly known as K.E.C, Dwarahat in 2015, India. Presently. He has research interest in Bio fuels, Boiler efficiency, Fluid flow and thermal analysis. He has 5 to 8 publications in international and national journals and conferences. He has filed two patents.

Shivasheesh Kaushik is an Assistant Professor at Shivalik College of Engineering, Dehradun, India. He received his M.Tech. from B.T.K.I.T formerly known as K.E.C, Dwarahat in 2015, India. Presently, he has research interest in Bio fuels pressure vessels and piping, plates and shells, composite materials and thermal analysis. He is life Associate Member (Membership Number: AM1840951) in IEI organization and Certified Charted Engineer from IEI Organization. He has 5 to 8 publications in international and national journals and conferences. He has filed two patents

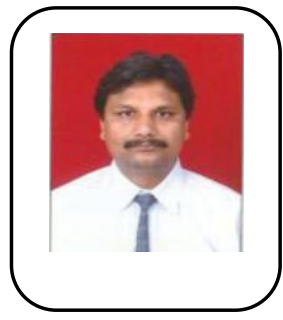

Dr. Satyendra Singh is an Associate Professor at BTKIT, Dwarahat, India. He received his Ph.D. from IIT Delhi, India. Presently he is Head of Department of Mechanical Engineering and Dean (Academics). He has research interest in finite element analysis, dynamics of structures, pressure vessels and piping, plates and shells, composite structures and thermal analysis. He is life member of Indian society of Technical Education and Fellow of Institution of Engineers (India). He has more than hundred publications in international and national journals and conferences. He has filed two patents.

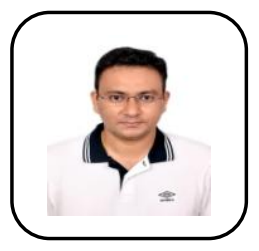

Dr.Rahul Kshetri, had complete their Bachelor degree from Govind Ballabh Pant Engineering College, Pauri Garhwal with the specialization of Production Engineering (Mechanical), also earned his master's (Manufacturing Engineering and Management) and Ph.D. from Department of Industrial and Production Engineering, G.B.P.U.A.T Pantnagar, U.S Nagar. Research work specialization of author is in the field of modeling of turning operation with published dozens of national and international paper and conferences. Author also Have published two books based on capacitive transducer and quality function deployment in fuzzy AHP.

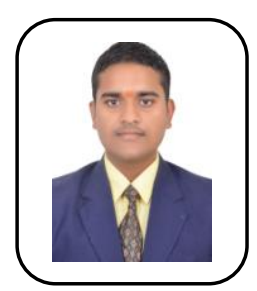

Mr. Rahul Pandey, is currently a scholar of sixth semester, pursuing Bachelor's degree in Technology from Mechanical Engineering department of Amrapali Institute of Technology, Haldwani, Uttarakhand, India. $\mathrm{He}$ has been consistent throughout his scholastics and has got four research papers published in international journals. He holds an affiliate membership of IMeche, United Kingdom and has certifications from Google in Fundamentals of Digital Marketing and in Manufacturing Technology I \& II from IIT Kanpur through NPTEL. 